\title{
Noise Pollution and Its Correlations with Occupational Noise-Induced Hearing Loss in Cement Plants in Vietnam
}

\author{
Tinh Thai ${ }^{1, * \mathbb{D}}$, Petr Kučera ${ }^{2}$ and Ales Bernatik ${ }^{1} \mathbb{D}$ \\ 1 Faculty of Safety Engineering, VŠB-Technical University of Ostrava, 70030 Ostrava, Czech Republic; \\ ales.bernatik@vsb.cz \\ 2 Department of Fire Protection, VŠB-Technical University of Ostrava, 70030 Ostrava, Czech Republic; \\ petr.kucera@vsb.cz \\ * Correspondence: thaixuantinh@gmail.com
}

Citation: Thai, T.; Kučera, P.; Bernatik, A. Noise Pollution and Its Correlations with Occupational Noise-Induced Hearing Loss in Cement Plants in Vietnam. Int. J. Environ. Res. Public Health 2021, 18, 4229. https://doi.org/10.3390/ ijerph18084229

Academic Editor: Luigi Vimercati

Received: 23 March 2021

Accepted: 15 April 2021

Published: 16 April 2021

Publisher's Note: MDPI stays neutral with regard to jurisdictional claims in published maps and institutional affiliations.

Copyright: (c) 2021 by the authors. Licensee MDPI, Basel, Switzerland. This article is an open access article distributed under the terms and conditions of the Creative Commons Attribution (CC BY) license (https:/ / creativecommons.org/licenses/by/ $4.0 /)$.

\begin{abstract}
Noise-Induced Hearing Loss (NIHL) is a global issue that is caused by many factors. The purpose of this study was to survey noise level to identify NIHL and its relationship with other factors in cement plants in Vietnam. Noise level was measured at one cement plant and three cement grinding stations located in the South of Vietnam. The audiometric data of exposed workers were surveyed to determine NIHL. Finally, the relationship between NIHL and noise level in cement plants was determined. The results show that noise level in almost all processes exceeded the permissible exposure limit (PEL). In this study, 42 cases (10\% of exposed workers) with occupational NIHL were found with mean age (SD) of 49 (9.0) years. All NIHL cases were found in the departments in which the noise level exceeded the PEL, which included quarry $(n=16)$, maintenance $(n=12)$, production $(n=10)$, co-waste processing $(n=3)$ and quality assurance $(n=1)$. There was a positive and significant correlation between the NIHL and the excessive noise exposure in the cement plants $(\mathrm{r}=0.89, p=0.04)$.
\end{abstract}

Keywords: cement manufacturing; noise-induced hearing loss; noise level

\section{Introduction}

Noise-induced hearing loss (NIHL) has long been recognized as an occupational disease, amongst copper workers from hammering on metal, blacksmiths in the 18th century, and shipbuilders or boilermakers after the Industrial Revolution [1]. It has been suggested that $12 \%$ or more of the global population is at risk of hearing loss from noise [2] The World Health Organization estimated that one-third of all cases of hearing loss can be attributed to noise exposure [3]. In cement plants, noise is typically one of the most harmful factors and is generated in many processes. Noise sources in a cement plant are varied and mainly include gas dynamic noise, which is induced by blower, air compressor and dust collector operation; mechanical noise, which is induced by machine operation, such as crushers, mills; electric-magnetic noise, which is induced by electric motors. The noise levels in some production areas, such as in the cement mill, air compressor, blower or crusher, in the cement grinding station ranged between 89 and $105 \mathrm{dBA}$ and exceeded the Vietnamese permissible exposure limit (PEL) ( $85 \mathrm{dBA} / 08$ working hours) [4]. Workers who are under long-term exposure to excessive noise level can develop noise-induced hearing loss (NIHL) [5].

In Vietnam, occupational NIHL is recognized as a work-related health condition and is compensated. According to Vietnamese legislation, the noise level in the workplace in all businesses is surveyed at least once a year, and workers who operate in areas which exceed the permissible exposure limit (PEL) undertake a yearly audiometric examination to determine whether there is occupational NIHL. However, a full hearing-conservation program has not yet been required by law, nor has it been adequately implemented by 
cement makers. The lack of awareness of NIHL among workers, employers and even healthcare professionals leads to the high prevalence of NIHL observed in Asian laborers [5]. In order to understand the correlations between noise level and the risk of NIHL in the cement industry in Vietnam, the purpose of this study was to (1) survey the noise level in the main processes of one cement plant and three cement grinding stations; (2) identify NIHL in cement plants; (3) analyze the correlations between NIHL and the noise level in cement manufacturing plants.

\section{Materials and Methods}

This study was conducted in November 2018 at one cement plant (S1) and three cement grinding stations $(\mathrm{S} 2, \mathrm{~S} 3, \mathrm{~S} 4)$ located in the South of Vietnam. The general information of study sites is described in Table 1.

Table 1. The General Information of Study Sites.

\begin{tabular}{cccccc}
\hline Site & Established Year & $\begin{array}{c}\text { Capacity } \\
\text { (Mt/Year) }\end{array}$ & $\begin{array}{c}\text { Full Time Equivalent } \\
\text { in 2018 }\end{array}$ & $\begin{array}{c}\text { Noise Exposed-Workers } \\
\text { in 2018 }\end{array}$ & Operation Type \\
\hline S1 & 1997 & 3.6 & 393 & 290 & Cement plant \\
S2 & 2003 & 0.5 & 88 & 40 & Cement grinding station \\
S3 & 2005 & 3.0 & 95 & 56 & Cement grinding station \\
S4 & 1996 & 1.5 & 113 & 32 & Cement grinding station \\
\hline
\end{tabular}

Firstly, the noise level was measured for 30 cement manufacturing sub-processes at the study sites in November 2018. At each measurement site, the noise level was measured in the workers' hearing zone for three minutes during each of 5 different working hours (7:30; 9:30; 11:30; 13:30; 15:30). These hours cover the duration of the day shift and represent the noise levels for all workers at that site, since operational processes are the same for all shifts. Noise level was measured during normal full operating conditions without interference from other factors, such as rain or traffic activities, and was generated continuously during measurements. Noise level was measured using a sound-level meter (Quest SoundPro SE, Oconomowoc, WI, USA), placed at the worker's working position and at a height of $1.4 \mathrm{~m}$ from the ground. Before measuring, the noise meter was calibrated to the Vietnamese legal requirement. For each measurement site, the equivalent noise level was calculated from the five measurements using the formula (1) [6]:

$$
\text { Leq }=10 \log \left(\frac{1}{n}\left[10^{0.1 L_{1}}+10^{0.1 L_{2}}+\ldots+10^{0.1 L_{n}}\right]\right)
$$

where Leq: A-weighted, is the equivalent steady sound level of noise energy averaged over time; $L_{n}$ : the $n$th sound level of $n$ sound levels $(n=5)$.

Secondly, the authors worked with the health practitioners who are in charge of occupational health checks at the plants. In 2018,418 workers ( $60.67 \%$ of excessive noiseexposed workers) at the study sites were sent to the Institute of Public Health, Ho Chi Minh City for NIHL test. The general processes to identify the occupational NIHL, applied in Vietnam, included (1) exposed workers were initially evaluated the auditory threshold at $4000 \mathrm{~Hz}$; (2) workers with a reduction threshold of $50 \mathrm{~dB}$ or greater at $4000 \mathrm{~Hz}$ were further tested at the frequency $500 \mathrm{~Hz}, 1000 \mathrm{~Hz}, 2000 \mathrm{~Hz}$ and $8000 \mathrm{~Hz}$; (3) the percentage hearing loss (PHL) was identified by using the Fowler-Sabine table [7]. Then, the percentage of impairment loss was compared to WHO NIHL criteria to define occupational NIHL. The grades of hearing impairment included slight or mild impairment with a hearing loss range from 26 to $40 \mathrm{~dB}$; moderate impairment with a hearing loss range from 41 to $60 \mathrm{~dB}$; severe impairment with hearing loss range from 61 to $80 \mathrm{~dB}$; profound impairment with a hearing loss range of $81 \mathrm{~dB}$ or greater [8].

Thirdly, the authors worked with Human Resources Departments at study sites to survey the age, working department, and length of service of occupational NIHL cases. 
Finally, the correlation between occupational NIHL and the noise level in the stages of the cement-making process was analyzed.

\section{Results and Discussion}

\subsection{Excessive Noise Level and Wide Range Distribution in Cement Plant}

The results of the noise level surveillance in one cement plant and three cement grinding stations reveal that the equivalent noise level in many processes of cement manufacturing exceeded the permissible exposure limit for an 8-hour shift, regulated by the Vietnamese Standard ( $85 \mathrm{dBA})$. The processes with an excessive noise level at the first study site (S1) included quarry, coal mill, cement mill, kiln, air compressor, and co-wasteprocessing area. The processes with an excessive noise level at the second study site (S2) included cement ball mill, air compressor room, and packer. The processes with an excessive noise level at the third study site (S3) was the vertical cement mill, and at the fourth study site (S4) this included the vertical cement mill and compressor room. The noise levels in the main processes of cement manufacturing plant ranged between $68.8 \mathrm{dBA}$ and 103.3 dBA, which workers were exposed to every single day. The noise levels at the study sites are shown in Table 2.

Table 2. The Equivalent Noise Level at the Cement Plants.

\begin{tabular}{|c|c|c|c|c|c|c|c|c|}
\hline \multirow{2}{*}{$\begin{array}{l}\text { Study } \\
\text { Sites }\end{array}$} & \multirow{2}{*}{ Process } & \multirow{2}{*}{ Area } & \multicolumn{5}{|c|}{ Equivalent Noise Level (dBA) } & \multirow{2}{*}{ Leq (dBA) } \\
\hline & & & $7: 30$ & $9: 30$ & 11:30 & $13: 30$ & $15: 30$ & \\
\hline \multirow{11}{*}{ S1 } & \multirow{4}{*}{ Quarry } & Drilling machine & 90.1 & 88.3 & 87.6 & 91.2 & 91.2 & 89.9 \\
\hline & & Cab of bulldozer & 87.7 & 88.2 & 83.1 & 82.4 & 85.6 & 86.0 \\
\hline & & Crusher of limestone & 93.4 & 95.3 & 97.4 & 99.1 & 99.0 & 97.4 \\
\hline & & Crusher hopper & 99.2 & 100.1 & 101.2 & 102.4 & 103.5 & 101.5 \\
\hline & \multirow{5}{*}{$\begin{array}{c}\text { Clinker and cement } \\
\text { production }\end{array}$} & Coal mill area & 89.3 & 83.2 & 87.8 & 88.3 & 90.2 & 88.3 \\
\hline & & Compressor room & 98.2 & 98.3 & 94.5 & 95.9 & 96.4 & 96.9 \\
\hline & & Raw mill & 89.7 & 90.8 & 91.3 & 91.6 & 92.3 & 91.2 \\
\hline & & Kiln area & 88.6 & 87.9 & 89.3 & 92.1 & 91.1 & 90.1 \\
\hline & & Cement mill & 88.6 & 90.3 & 87.9 & 91.2 & 92.1 & 90.3 \\
\hline & Quality Assurance & Lab room & 82.3 & 80.3 & 81.5 & 84.2 & 85.5 & 83.2 \\
\hline & Co-waste processing & Waste cutter and feeding chute & 88.3 & 92.5 & 88.6 & 92.4 & 90.2 & 90.8 \\
\hline \multirow{7}{*}{$\mathrm{S} 2$} & Unloading material & Unloading & 72.1 & 72.4 & 73.5 & 76.1 & 73.5 & 73.8 \\
\hline & Storage & Storage & 67.8 & 66.3 & 68.5 & 72.1 & 66.8 & 68.8 \\
\hline & Pre-grinding & Roller press & 83.5 & 82.3 & 82.4 & 84.5 & 86.3 & 84.1 \\
\hline & \multirow[b]{2}{*}{ Grinding } & Ball mill & 95.2 & 92.1 & 90.0 & 94.3 & 92.7 & 93.2 \\
\hline & & Air compressor & 89.3 & 91.4 & 88.4 & 91.3 & 88.2 & 89.9 \\
\hline & \multirow{2}{*}{ Dispatch } & Packer & 86.2 & 84.3 & 85.3 & 86.7 & 83.4 & 85.3 \\
\hline & & Truck loader & 72.3 & 72.5 & 74.5 & 76.8 & 77.5 & 75.2 \\
\hline \multirow{6}{*}{ S3 } & Unloading material & Jetty & 71.3 & 77.8 & 73.3 & 75.4 & 77.5 & 75.7 \\
\hline & Storage & Warehouse & 76.3 & 75.4 & 77.2 & 75.5 & 78.9 & 76.9 \\
\hline & Raw material feeding & 1st floor & 77.8 & 83.5 & 80.8 & 81.3 & 83.2 & 81.7 \\
\hline & Grinding & Vertical mill & 84.7 & 86.2 & 90.4 & 92.0 & 87.8 & 89.0 \\
\hline & \multirow{2}{*}{ Dispatch } & Packer & 80.8 & 85.3 & 81.2 & 80.7 & 80.2 & 82.1 \\
\hline & & Truck loader & 75.3 & 72.6 & 73.2 & 74.9 & 76.5 & 74.7 \\
\hline \multirow{6}{*}{$\mathrm{S} 4$} & Raw material preparation & Pozzolana crusher & 82.3 & 81.2 & 84.3 & 84.3 & 81.5 & 82.9 \\
\hline & Storage & Pozzolana storage & 72.1 & 75.2 & 76.4 & 74.3 & 75.2 & 74.9 \\
\hline & \multirow{2}{*}{ Grinding } & Vertical mill & 88.1 & 89.6 & 89.3 & 88.7 & 89.3 & 89.0 \\
\hline & & Compressor & 93.2 & 103.6 & 105.4 & 104.3 & 103.2 & 103.3 \\
\hline & \multirow{2}{*}{ Dispatch } & Packer & 81.2 & 80.4 & 83.2 & 82.3 & 81.2 & 81.8 \\
\hline & & Truck loader & 77.4 & 80.2 & 79.2 & 78.4 & 75.2 & 78.4 \\
\hline
\end{tabular}


In a full cement manufacturing plant (S1), the equivalent noise level in almost all processes exceeded the permissible exposure limit (PEL) regulated by the Vietnamese standard or by the National Institute for Occupational Safety and Health (NIOSH) (85 dBA for 08 working hours). At the quarry, the first process in cement manufacturing, the equivalent noise level in all sub-processes, including drilling, bulldozer operation, limestone crusher, and crusher hopper, exceeded the PEL and ranged between $86.0 \mathrm{dBA}$ and $101.5 \mathrm{dBA}$. The clinker production process with two main sub-processes included raw material grinder and rotary kiln. The equivalent noise level at raw material grinder was $91.2 \mathrm{dBA}$ and exceeded the PEL by $6.2 \mathrm{dBA}$, and at the kiln, the noise level was $90.1 \mathrm{dBA}$, which exceeded the PEL by $5.1 \mathrm{dBA}$. In the parallel process, the equivalent noise level at the coal mill was detected as the highest noise level, at $88.3 \mathrm{dBA}$, which is $3.3 \mathrm{dBA}$ above the PEL. At the cement production process, the equivalent noise level at the cement mill was $90.3 \mathrm{dBA}(+5.3 \mathrm{dBA})$ and in co-waste processing, the equivalent noise level at the waste cutter was $90.8 \mathrm{dBA}$, which exceeded the PEL. The equivalent noise level at the quality assurance process was 83.2 dBA, but at times, the noise level was $85.5 \mathrm{dBA}$.

At the three cement grinding plants $(\mathrm{S} 2, \mathrm{~S} 3, \mathrm{~S} 4)$, the equivalent noise level ranged between $68.8 \mathrm{dBA}$ and $103.3 \mathrm{dBA}$. The highest equivalent noise level in these processes at $\mathrm{S} 2$ was $93.2 \mathrm{dBA}$; at S3 it was $89.0 \mathrm{dBA}$; at S4 it was $103.32 \mathrm{dBA}$. The noise source in cement manufacturing varies with a high level and a wide distribution.

The above results reveal that the noise level in the main processes of cement plants exceeded the PEL, and these results are comparable to other studies. Previous studies showed that the processes in the cement plant that exceeded the PEL included quarry (98 dBA), crusher room (106 dBA), ball mill room (101 dBA), raw material mill (103 dBA), rotary kiln (93 dBA), coal mill (102 dBA), and air compressor room (95 dBA) [8-11]. The equivalent noise level in the cement industry is comparable to the noise levels in other industries, such as a textile mill in Mainland China (84-103 dBA), transport in India (89-106 dBA), agriculture in Japan (82-99 dBA), and oil refinery in Taiwan (73-89 dBA) [5].

Noise is typically one of the most hazardous factors in cement manufacturing. It has the potential to lead to occupational deafness [10], and workers who are daily expose to such excessive noise levels for a prolonged period will face considerable social and physiological impacts, including NIHL [12].

\subsection{Noise-Induced Hearing Loss in Cement Plant}

A total of forty-two occupational NIHL cases have been recognized for the period of operations from 1996 to 2018 in the study sites. The number of the occupational NIHL cases found at study sites from 1996 to 2018 is shown in Table 3. The characteristics of NIHL and non NIHL cases are shown in Table 4.

Table 3. The Number of the Occupational NIHL Cases Found at Study Sites from 1996 to 2018.

\begin{tabular}{|c|c|c|c|c|c|c|c|c|c|c|c|c|c|c|c|c|}
\hline Site & 2003 & 2004 & 2005 & 2006 & 2007 & 2008 & 2009 & 2010 & 2011 & 2012 & 2013 & 2014 & 2015 & 2016 & 2017 & 2018 \\
\hline S1 & 1 & 2 & 0 & 0 & 1 & 0 & 3 & 0 & 11 & 7 & 1 & 5 & 10 & 0 & 0 & 0 \\
\hline S2 & 0 & 0 & 0 & 0 & 0 & 0 & 0 & 0 & 0 & 0 & 0 & 1 & 0 & 0 & 0 & 0 \\
\hline S3 & 0 & 0 & 0 & 0 & 0 & 0 & 0 & 0 & 0 & 0 & 0 & 0 & 0 & 0 & 0 & 0 \\
\hline S4 & 0 & 0 & 0 & 0 & 0 & 0 & 0 & 0 & 0 & 0 & 0 & 0 & 0 & 0 & 0 & 0 \\
\hline
\end{tabular}

The first case of occupational NIHL was detected in 2003 at the cement plant (S1) after six years of operation. During the first ten years of operation at S1, three occupational NIHL cases were found and, within next five years, through 2011, an additional fifteen occupational NIHL cases had been recorded. By the end of 2015, after 18 years of operation, forty-one occupational NIHL cases were found at S1 and one case was recorded at S2. There have been no cases of occupational NIHL detected at S3 or S4 so far. Almost all occupational NIHL cases were found at S1 $(n=41)$, which had been in operation for 21 years, and one case was found at S2. For employees with NIHL $(n=42)$, the mean 
duration of their employment when NIHL detected was 12 years. The first case of NIHL was found after 2 years of employment at S1.

Table 4. The Characteristics of NIHL and Non-NIHL Cases at Study Sites.

\begin{tabular}{|c|c|c|c|c|}
\hline \multicolumn{2}{|c|}{ Variable } & $\begin{array}{l}\text { Audiometric Participants } \\
\qquad(n=418)\end{array}$ & $\begin{array}{l}\text { NIHL Cases } \\
\quad(n=42)\end{array}$ & $\begin{array}{c}\text { Non-NIHL Cases } \\
\quad(n=376)\end{array}$ \\
\hline & & Mean (SD) & Mean (SD) & Mean (SD) \\
\hline \multicolumn{2}{|c|}{ Age (years) } & $38.6(9.0)$ & $49(9.0)$ & $37.4(8.5)$ \\
\hline \multicolumn{5}{|c|}{ Gender } \\
\hline \multicolumn{2}{|c|}{ Male } & 402 & 42 & 360 \\
\hline \multicolumn{2}{|c|}{ Female } & 16 & 0 & 16 \\
\hline \multicolumn{5}{|c|}{ Age group (years) } \\
\hline \multicolumn{2}{|c|}{20 years old and below } & 0 & 0 & 0 \\
\hline \multicolumn{2}{|c|}{21 to 30 years old } & 77 & 0 & 77 \\
\hline \multicolumn{2}{|c|}{31 to 40 years old } & 181 & 1 & 180 \\
\hline \multicolumn{2}{|c|}{41 to 50 years old } & 106 & 19 & 87 \\
\hline \multicolumn{2}{|c|}{51 years old and above } & 54 & 22 & 32 \\
\hline \multicolumn{2}{|c|}{ Length of working service (years) } & $12.6(6.2)$ & $21(3.5)$ & $11.8(6.1)$ \\
\hline \multicolumn{5}{|c|}{ Hearing loss degree } \\
\hline \multicolumn{2}{|c|}{$20-40 \mathrm{~dB}$} & NA & 30 & NA \\
\hline \multicolumn{2}{|c|}{$41-60 \mathrm{~dB}$} & NA & 10 & NA \\
\hline \multicolumn{2}{|c|}{$61-80 \mathrm{~dB}$} & NA & 2 & NA \\
\hline \multicolumn{5}{|c|}{ Hearing loss level (dB) } \\
\hline \multirow{4}{*}{ Left ear } & $500 \mathrm{~Hz}$ & NA & $35.4(11.1)$ & NA \\
\hline & $1000 \mathrm{~Hz}$ & NA & $39.6(9.5)$ & NA \\
\hline & $2000 \mathrm{~Hz}$ & NA & $37.9(9.9)$ & NA \\
\hline & $4000 \mathrm{~Hz}$ & NA & $53.9(7.7)$ & NA \\
\hline \multirow{4}{*}{ Right ear } & $500 \mathrm{~Hz}$ & NA & $35.3(10.7)$ & NA \\
\hline & $1000 \mathrm{~Hz}$ & NA & $38.6(10.6)$ & NA \\
\hline & $2000 \mathrm{~Hz}$ & NA & $38.4(9.5)$ & NA \\
\hline & $4000 \mathrm{~Hz}$ & NA & $54.6(8.0)$ & NA \\
\hline \multicolumn{5}{|c|}{ Percentage hearing loss (\%) } \\
\hline \multicolumn{2}{|c|}{ Left ear } & NA & $35.8(14.7)$ & NA \\
\hline \multicolumn{2}{|c|}{ Right ear } & NA & $35.5(15.0)$ & NA \\
\hline
\end{tabular}

NA: Not applicable.

The mean (SD) age of excessive noise exposed workers surveyed in $2018(n=418)$ was 38.6 (9.0) years; the youngest workers were 22 years old $(n=8)$ and the oldest workers were 59 years old $(n=4)$. The mean (SD) age of NIHL cases was $49(9.0)$ years and mean (SD) age of the non NIHL cases was 37.4 (8.5) years. The mean age of NIHL cases found at the study sites was higher than the mean age of the audiometric participants in 2018 and of the non-NIHL cases. In this study, the youngest worker that suffered from NIHL was 36 years old and the oldest worker was 57 years old. This finding was comparable with the study among metallurgical company workers in Brazil, which reported that the mean age of those with NIHL was 50 (12) years [13] and the mean age of participants at six quarries in Malaysia with NIHL was 35 (9) years [9].

The percentages of NIHL cases with age groups from 41 to 50 years old and above 50 years old were $45 \%(n=19)$ and $52 \%(n=22)$, respectively, which was higher than that for the same age group of non-NIHL workers.

In this study, the mean (SD) length of working service of all audiometric participants surveyed in 2018 was 12.6 (6.2) years. The mean (SD) length of working service of nonNIHL cases was 11.8 (6.1) years. The mean (SD) length of working service of NIHL cases was 21 (3.5) years, which was higher than that of the non-NIHL cases. 


\subsection{The Correlation between the Occupational NIHL and the Excessive Noise Level}

In this research, all of the occupational NIHL cases were discovered at departments where the equivalent noise level exceeded PEL ( $85 \mathrm{dBA} / 8$ hours). In total, 16 occupational NIHL cases (38\%) were discovered at the quarry, where the equivalent noise level ranged between $86.0 \mathrm{dBA}$ and $101.5 \mathrm{dBA} ; 12$ cases $(29 \%)$ were discovered in the maintenance department, and 10 cases $(24 \%)$ in the production department where the equivalent noise level ranged between $88.3 \mathrm{dBA}$ and $96.9 \mathrm{dBA} ; 3$ cases $(7 \%)$ came from the co-waste processing department, where the equivalent noise level was $90.8 \mathrm{dBA}$, and 1 case $(2 \%)$ came from the quality assurance department, where the equivalent noise level was $83.2 \mathrm{dBA}$; however, sometimes during operation the noise level exceeded $85 \mathrm{dBA}$.

The correlation between the number of NIHL cases in different departments and the excessive noise level in their departments was significant $(\mathrm{r}=0.89, p=0.04)$. The relationship between NIHL and prolonged high-noise exposure was published in other studies. A study in Ghana showed that the noise level in corn mills exceeded the PEL ( $85 \mathrm{dBA}, \mathrm{WHO}$, 1999) and 23\% of workers in corn mills presented with evidence of NIHL [14]. This finding was also comparable to those reported in other studies [15-17].

\subsection{The Degree of NIHL in Cement Plants}

Almost all workers in cement plants had been working in environments with a high noise level. In $2018,74 \%$ workers $(n=393)$ at $\mathrm{S} 1,45 \%$ workers $(n=88)$ at $\mathrm{S} 2,59 \%$ workers $(n=95)$ at $\mathrm{S} 3$ and $28 \%$ workers $(n=113)$ at $\mathrm{S} 4$ were often exposed to the high noise level in their daily lives. Through this exposure, and improper NIHL-prevention programs, workers in cement manufacturing plants are at a high risk of NIHL.

The degree of hearing loss in this study ranged from mild to severe, based on the WHO classification [8]. In this study, of 42 workers with NIHL, 30 cases $(71.4 \%)$ had mild hearing loss, 10 cases $(23.8 \%)$ had moderate hearing loss and 2 cases $(4.8 \%)$ had severe hearing loss. A study of NIHL among quarry workers in the North-Eastern State of Malaysia showed that $42 \%(n=23)$ had mild and moderate hearing loss and $16 \%(n=9)$ had severe hearing loss [9]. In addition, a study of NIHL in cement plants in Nigeria reported that $67 \%$ of workers had mild sensorineural hearing loss and $12 \%$ had moderate hearing loss in the right ear [18].

\subsection{Hearing Conservation Program}

The hearing conservation program ( $\mathrm{HCP}$ ) comprises a set of coordinated measures to prevent the development of occupational NIHL [18]. The HCP is an essential service that employers are required to implement in many developed countries, such as The United States of America, Canada, Argentina. The effectiveness of an HCP has been studied and reported in many studies [19-21]. A specific HCP needs to be considered and addressed by the cement makers in Vietnam to diminish NIHL. The elements of the HCP included noise hazard identification and noise exposure monitoring; controlling noise exposure; hearing protection devices; audiometric testing; hazard communication; education and training; recordkeeping; continuous monitoring and improvement.

The limitations of this study were that data concerning general health conditions and whether hearing-protection devices were habitually used during daily work activities were not recorded. These factors could affect the incidence of hearing loss of workers in cement manufacturing plants.

\section{Conclusions}

Noise is one of the main occupational health hazards in the main processes of cement manufacturing plants. Long-term exposure to excessive noise pressure levels exceeding the PEL ( $85 \mathrm{dBA}$ ) within cement manufacturing processes could lead to NIHL. There was a positive correlation between the number of cases of NIHL and excessive noise exposure in cement manufacturing processes. The degree of NIHL in cement plants ranged between mild and severe loss of hearing. In addition, the prevalence and variety of noise distribution 
in the day-to-day exposure of workers in cement plants could account for the increase in the number of NIHL cases in the cement plant. It is necessary for cement makers and health and safety personnel in cement plants in Vietnam to enforce the hearing conservation program to reduce the risks of NIHL for workers.

Author Contributions: The study was designed by T.T.; data collection, analysis, interpretation and draft manuscript preparation were undertaken by T.T.; manuscript review and editing by P.K., A.B. All authors have read and agreed to the published version of the manuscript.

Funding: This study was not funded.

Institutional Review Board Statement: The ethical review and approval were waived for this study, due to (1) the primary contents of this manuscript were to measure the noise level in the cement plants, then analyzing the relationship between NIHL and noise level in the cement plants; (2) the data of NIHL at the study sites was provided by site's representatives. For the step of surveying the age, working departments, length of working service of the occupational NIHL cases that authors were contacted directly to Human Resources representatives at the study sites, explained them the purposes of the study and got the agreement that the details of participants were not included in the manuscript and the privacy information of the participants will be kept confidential.

Informed Consent Statement: Informed consent was obtained from all subjects involved in the study.

Data Availability Statement: Data from this study are available upon request.

Acknowledgments: The authors extend their sincere gratitude to the management teams of the study sites for supporting this research. The authors would also like to thank the health practitioners, clinical officers, environmental officers, and human resources officers at the study sites for their support in the data survey. Finally, we would like to thank Assistant PhD Thi Ngoc Bao Dung, Ton Duc Thang University for her support.

Conflicts of Interest: The authors have no conflicts of interest to declare.

\section{References}

1. Le, N.T.; Straatman, L.V.; Lea, J.; Westerberg, B. Current insights in noise-induced hearing loss: a literature review of the underlying mechanism, pathophysiology, asymmetry, and management options. J. Otolaryngol. Head Neck Surg. 2017, 46, 41-56. [CrossRef] [PubMed]

2. Alberti, P.W.; Symons, F.; Hyde, M.L. Occupational Hearing Loss The Significance of Asymmetrical Hearing Thresholds. Acta Otolaryngol. 1979, 87, 255-263. [CrossRef] [PubMed]

3. Noise and Hearing Loss. 1990. Available online: https:// consensus.nih.gov/1990/1990noisehearingloss076html.htm (accessed on 1 June 2019).

4. Thai, X.T.; Kucera, P. Control of noise level and its effects on workers in Hiep Phuoc Cement Grinding Plant, Holcim Vietnam. In Proceedings of the 1st International Conference on Environmental Technology and Innovations, Ho Chi Minh City, Vietnam, 23-25 November 2016.

5. Fuente, A.; Hickson, L. Noise-induced hearing loss in Asia. Int. J. Audiol. 2011, 50, 3-10. [CrossRef] [PubMed]

6. Work Safe BC, Basic Noise Calculations. 2007. Available online: https://www.worksafebc.com/en/resources/health-safety/ books-guides/basic-noise-calculations?lang=en (accessed on 19 May 2016).

7. Evaluation and Compensation of Occupational Hearing Loss in the United States. Available online: https://apps.dtic.mil/sti/ citations / ADA031271 (accessed on 1 June 2019).

8. World Health Organization. Report of the Informal Working Group on Prevention of Deafness and Hearing Impairment Programme Planning. 1991. Available online: https:/ /apps.who.int/iris/handle/10665/58839 (accessed on 13 May 2019).

9. Ismail, A.F.; Daud, N.A.; Ismail, Z.; Baharudin, A. Noise-Induced Hearing Loss Among Quarry Workers in a North-Eastern State of Malaysia: A Study on Knowledge, Attitude and Practice. Oman Med. J. 2013, 28, 331-336. [CrossRef] [PubMed]

10. Zhang, C.; Yuan, S.; Li, D. Comprehensive Control of the Noise Occupational Hazard in Cement Plant. Int. Symp. Saf. Sci. Eng. China 2012, 43, 186-190.

11. Mndeme, F.G.; Mkoma, S.L. Assessment of work zone noise levels at a cement factory in Tanga, Tanzania. Ethiop. J. Environ. Stud. Manag. 2012, 5, 225-231. [CrossRef]

12. Nelson, D.; Nelson, R.; Concha-Barrientos, M.; Fingerhut, M. The Global Burden of Occupational Noise-Induced Hearing Loss. Am. J. Ind. Med. 2005, 48, 446-458. [CrossRef] [PubMed]

13. Guerra, M.R.; Lourenco, P.M.; Bustamante-Teixeira, M.T.; Alves, M.J. Prevalence of Noise-Induced Hearing Loss in Metallurgical Company. Rev. Saude Publica 2005, 39, 238-244. [CrossRef] [PubMed] 
14. Boateng, C.A.; Amedofu, G.K. Industrial Noise Pollution and Its Effects on The Hearing Capabilities of Workers: A study from saw mills, printing presses and corn mills. Afr. J. Health Sci. 2004, 11, 55-60. [CrossRef] [PubMed]

15. Dube, K.J.; Ingale, L.T.; Ingale, S.T. Hearing impairment among workers exposed to excessive levels of noise in ginning industries. Noise Health 2011, 13, 348-355. [CrossRef] [PubMed]

16. Ologe, F.E.; Akande, T.M.; Olajide, T.G. Occupational noise exposure and sensorineural hearing loss among workers of a steel rolling mill. Eur. Arch. Otorhinolaryngol. 2006, 263, 618-621. [CrossRef] [PubMed]

17. Minja, B.M.; Moshi, N.H.; Riwa, P. Noise Induced Hearing Loss Among Industrial Workers In Dar Es Salaam. East Afr. Med. J. 2003, 80, 298-302. [CrossRef] [PubMed]

18. Ali, A.; Garandawa, H.H.; Nwawolo, C.; Somefun, O. Noise-Induced Hearing Loss at Cement Company, Nigeria. Online J. Med. Med. Sci. Res. 2012, 1, 49-54.

19. Fonseca, V.R.; Marques, J.; Panegalli, F.; Goncalves, C.G.O.; Souza, W. Prevention of the Evolution of Workers' Hearing Loss from Noise-Induced Hearing Loss in Noisy Environments through a Hearing Conservation Program. Int. Arch. Otorhinolaryngol. 2016, 20, 43-47. [CrossRef] [PubMed]

20. Heyer, N.; Morata, T.C.; Pinkerton, L.E.; Brueck, S.E.; Stancescu, D.; Panaccio, M.P.; Kim, H.; Sinclair, J.S.; Waters, M.A.; Estill, C.F.; et al. Use of historical data and a novel metric in the evaluation of the effectiveness of hearing conservation program components. Occup. Environ. Med. 2011, 68, 510-517. [CrossRef] [PubMed]

21. Amedofu, G.K. Effectiveness of hearing conservation program at a large surface gold mining company in Ghana. Afr. J. Health. Sci. 2007, 14, 49-53. [CrossRef] 